\title{
Mechanical Properties and Mix Design of Geopolymer concrete - A review
}

\author{
Vemundla Ramesh ${ }^{1}$, Dr.Koniki Srikanth ${ }^{2}$ \\ ${ }^{1}$ PG student, Civil Engineering Department, GRIET, Hyderabad, India. \\ ${ }^{2}$ Associate Professor, Civil Engineering Department, GRIET, Hyderabad, India.
}

\begin{abstract}
Geo-polymer concrete (GPC) is a most viable solution to cement as the raw materials depleting down the years and, many countries have started imposing carbon taxes. After a review for the literature reveals that there is no proper mix design procedure developed yet. GPC has better mechanical properties when compared to normal concrete. Curing conditions, setting times, workability, alkaline solution to binder ratios, molarity of alkaline solution, $\mathrm{Na}_{2} \mathrm{SiO}_{3} / \mathrm{NaOH}$ and $\mathrm{SiO}_{2} / \mathrm{Al}_{2} \mathrm{O}_{3}$ ratios play an important role to develop GPC. This paper presents an overview of Geopolymarization process, mechanical properties and mix design of GPC. Proper mix design of geopolymer concrete can produce desired mechanical properties for ambient curing condition. And geopolymer concrete can consider as eco-friendly construction material. This paper deals with study of advancement in mix design and mechanical properties of geopolymer concrete.
\end{abstract}

\section{Introduction}

Concrete is known to be the most extensively used material in construction of buildings, roads, bridges, retaining walls etc. Normal concrete is prepared by using binding material called Portland cement along with aggregates. It is calculable that the necessity of cement in India goes to be triumphant in half a billiontonnesthrough 2020 and there will be an insufficiency of 0.23 billiontonnes( $\sim 58 \%)$ and also the demand for cement has been without end growing attributable to enlarged infrastructural things to do in the country like India[1]. The production of cement in large amounts has a huge impact on limestone reserves as well as on Environment and it is a highly fuel or energy consuming process, generating 1 ton of $\mathrm{CO}_{2}$ to generate 1 ton of cement [2-4]. Construction industries are very much interested to adopt sustainable, alternative solution for OPC without compromising strength and durability properties and to avoid emission of greenhouse gases also [5]. Geopolymers are the best solution to replace ordinary Portland cement. Geopolymers are inorganic polymeric materials with a chemical composition much like zeolites but owning an amorphous shape. Geopolymers can be seen as man-made rocks. They can be made by means of reacting strong alumino-silicates with a notably focused aqueous alkali hydroxide or silicate solution. The chemistry and nomenclature of inorganic polymers was first mentioned exhaustively by Joseph Davidovits[6]. Geopolymer materials were utilized byancient Egyptians to build pyramids during 2630 BCE-2611 BCE hence it is an ancient construction material. Growing industrialization leads to the production of waste by products like rice husk ash, fly ash, ground granulated blast furnace slag, which contain pozzolanic character. Dumping of these industrial wastes is a challenging task. If we can use these materials as source materials of GPC not only the dumping problem is solved but also the environmental friendly binding material can be produced[7].GPC can generally be a mixture of several source materials like fly ash, ground granulated blast furnace slag, silica fume, rice husk ash and recently added materials like alccofineetc and the activators such as sodium hydroxide and sodium silicate in proper proportions [813].The wellspring of aluminosilicate and basic activator are significant elements of the geopolymer materials. In spite of the fact that the polymerization procedure of geopolymer materials is as yet questionable, it was discovered that the mechanical properties of the geopolymer materials are affected altogether by the synthetic piece of originmaterials and soluble activators [14]. Blend of palm oil fuel 
ash(POFA) and pulverized fuel ash can also be used as source material to produce GPC along with sodium silicate and sodium hydroxides as alkaline liquids[19]. These source materials when activated with alkali solution give on to the development of Si-O-Al bonding, this is very important to achieve polymerization process [20-27]. Although geopolymer concrete is a good innovative idea to replace ordinary or conventional concrete, it has its own limitations like high financial risk to work with the new revolutionary material and understanding the properties of GPC is a difficult task as there is no particular code of practice till date $[8,25,28]$. Chemical composition of various source materials used in GPC may vary depending on the type of material procured and place of procurement. So always permissible care should be taken before procuring the material and checking the micro structure to know the suitability of the material to be used as source material of GPC [29]. Chemical composition of various source material by X- Ray fluorescence (XRF) analysis are given below in Table1.

Table 1. Chemical composition of various source materials

\begin{tabular}{|c|c|c|c|c|c|c|c|c|}
\hline \multirow{2}{*}{ constituents } & \multicolumn{8}{|c|}{ Chemical composition (\% by mass) } \\
\cline { 2 - 9 } & $\mathbf{S i O}_{2}$ & $\mathbf{A l}_{2} \mathbf{O}_{3}$ & $\mathbf{F e}_{2} \mathbf{O}_{3}$ & $\mathbf{S O}_{3}$ & $\mathbf{C O O}$ & $\mathbf{M g O}$ & $\mathbf{N a}_{2} \mathbf{O}$ & LOI* $^{*}$ \\
\hline Fly ash[22] & 55.3 & 25.8 & 5.5 & 0.3 & 2.9 & 0.8 & - & 3.2 \\
\hline GGBS [8] & 34.06 & 20 & 0.8 & 0.9 & 32.6 & 7.89 & NIL & 3.72 \\
\hline Alccofine[32] & 32.84 & 22 & 2.5 & 0.3 & 36.10 & 4 & 0.34 & 0.49 \\
\hline MK[33] & 59 & 37.5 & 1.3 & - & 0.1 & 0.3 & 0.2 & - \\
\hline $\begin{array}{c}\text { Pond fly } \\
\text { ash[32] }\end{array}$ & 61.69 & 23.08 & 5.05 & 0.08 & 4.80 & 1.01 & 0.32 & 1.05 \\
\hline PFA[19] & 46.7 & 35.9 & 5 & - & 3.9 & 0.8 & 0.6 & 1 \\
\hline POFA[19] & 53.5 & 1.9 & 1.1 & - & 8.3 & 4.1 & 1.3 & 18 \\
\hline
\end{tabular}

${ }^{*}$ LOI:loss of ignition

\section{Significance of the study}

There is a necessity to replace ordinary Portland cement and conventional concrete to avoid depletion of lime stone reserves, high carbon emission and to introduce a revolutionary material which is to be consumed in high quantity on daily basis. A lot of research is being done on GPC but there is no proper code of practice available hence it is required to analyze the mechanical properties, setting times and workability characteristics. Guidelines to prepare mix design and strength characteristics of GPC were reviewed.

\section{Mechanical properties of GPC}

For a material like concrete, mechanical properties play key role as the strength can be decided by this properties only.Compressive strength is considered as the supreme property to get a clear idea about strength of the given concrete[15]. Recent work on geopolymer concrete showed that manufacturing process, curing period and curing temperature is highly affected compressive strength of geopolymerconcrete[12]. Major test to be performed to check the mechanical properties of GPC are compressive strength test. The procedure and equipment to be used to find compressive strength of GPC is same as conventional concrete only but the difference is related to curing.
Normal concrete is generally water cured but GPC is cured either by oven curing or ambient curing. Ambient curing is now adopted many researchers as there is availability problem for oven curing in many of the cases.

\subsection{Preparation of alkaline solution}

Preparation of alkaline solution is to be done carefully to get required concentration of the solution and to avoid unnecessary problems. Mishandling may harm the person who is mixing the solution as the reaction takes place due to mixing is exothermic in nature. First of all $\mathrm{NaOH}$ pellets of required quantity are to be deliquesce in fresh water in order to develop sodium hydroxide solution of required molarity.Sodium silicates solution to sodium hydroxide solution ratio is to be maintained depending on GPC mix, many researchers adopted that ratio to be $2.5[5,8,14,25,26]$ as it is giving good results it is required to store the solution for 24 hours at room temperatureto avoid exothermic action when added to source material and relative humidity is maintained about $65 \%$ before it is used for casting [8].

\subsection{Compressive strength of GPC}

Compressive strength gives the resistance offered by concrete against buckling, just like normal concrete 
cube specimens of size 150 X 150 X $150 \mathrm{~mm}$ geopolymer concrete cubesare also casted but curing condition is completely different, it depends on mix design and availability oven curing apparatus. Molar concentration of alkaline solution affect the strength of cube prepared. Usage of fly as as source material of GPC compressive strength is found to be increased with higher molar concentration of $\mathrm{NaOH}[20-22]$. Curing time is also influence compressive strength given in figure $1[11]$.

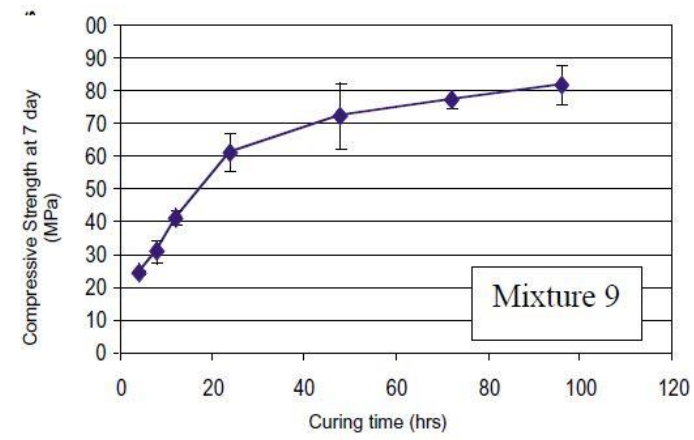

Fig.1.Influence of curing time on compressive strength[11]

Alkaline solution to binder ratio, proportions of source materials will effect workability and compressive strength of concrete. GGBS is substituted in the place of fly ash result in higher compressive strength due to thedevelopment of high Calcium Silicate Hydrate gel [8]. As the molarity of the $\mathrm{NaOH}$ increases strength of the GPC concrete specimen also increases but due to economic considerations the molarity of $\mathrm{NaOH}$ is limited accordingly[22]. Compressive strength is also altered by temperature of curing. Geopolymerization evolves some heat but it is relatively less when compared to OPC, addition of alccofine slightly increase the heat evolved in the process of geopolymerization. Compressive strength is slightly less when geopolymers cured at room temperature [32].

\section{Mix design of GPC}

Mix design of materials like conventional concrete and geopolymer concrete always play a crucial role in strength, durability and economy point of view. There are mix design methods for conventional concrete and a even a code of practice[16] is also available to design the mixes of normal concrete but as of now there is no particular code of practice for the mix design of geopolymer concrete. Many researchers designed the trial mixes based on standard code of practice for normal concrete,compressive strength, quantity of source material, setting time and workability, proportions of source materials $[8,14]$, molarity of alkaline solution [23] and few used their own convenient methodology to design like Taguchi method [30]. Most of the researchers have adopted fly ash and GGBS as source materials because fly ash is containing silica and alumina and GGBS is rich in calcium made the perfect combination to develop geopolymer concrete with ease. Recently discovered material such as alccofine can replace GGBS and give good mixture of GPC but it has its own limitations[32]. GPC can be designed by using following guidelines of IS 10262-2019 and IS 456-2000 but we need to change certain things accordingly as the curing conditions are different when compared to conventional concrete and even it is more convenient to use the design procedures of other researchers because of the reason that they would have changed the guidelines to mix design according to the curing conditions of GPC. Alkaline to binder ratio, fly ash to GGBS ratio, type of curing and age of curing are the major criteria to be considered $[8,14,35]$. Slump value needs to be noted to check the workability of each and every specimen of different proportions.Geopolymer specimens were generally demoulded after 24 hours and left for curing. If it is outdoor curing specimens need to be kept outside at a variable temperature of 25 to 35 degree centigrade and there is no need for humidity control as the specimens were cured by outdoor curing. GPC cubes need to be kept in 60 degree centigrade if the cubes are cured by oven and strength is calculated for 7 and 28 days [8].

\section{Future scope of the study}

Introducing a revolutionary material which can replace conventional concrete and gives good mechanical and durability properties is not so easy as the material is not feasible in all the cases. There should be some awareness to use GPC over normal concrete not only to get early strength but also to save environmental issue. Mix design and curing conditions have a great impact on strength of GPC so the research can be elongated to examine the properties of GPC at different curing conditions including laboratory and field conditions also.There is a scope to study the structural behavior of GPC members.

\section{Conclusions}

After reviewing several papers it is concluded that

- Geopolymerconcrete is the most effective way to replace conventional concrete in view of economic and eco-friendly considerations.

- Geopolymer concrete is well suited for high strength and high performance concrete and it also has the resistance to chemical attacks; 
- GGBS oralccofine can be substituted in the place of fly ash to improve the compressive strength of concrete for any curing conditions type but workability and setting will be reduced.

- Sodium silicates to sodium hydroxide ratio of 2.5 gives good results when compared to other ratios.

- An appropriate code of practice has to bedevelopedfrom past data.

\section{References}

1. Patankar, S. V., Ghugal, Y. M., \&Jamkar, S. S. (2015). Mix design of fly ash based geopolymer concrete. In Advances in Structural Engineering (pp. 1619-1634). Springer, New Delhi.

2. Davidovits, J. (1984). U.S. Patent No. 4,472,199. Washington, DC: U.S. Patent and Trademark Office.

3. Joseph, D. (1994). Global warming impact on the cement and aggregate industries. Geopolymer Institute Saint-Quention, France. World Resour. Rev, 6, 263-278.

4. J. Davidovits, High-alkali cements for 21 st century concretes, Special Publication 144 (1994) 383-398.

5. Junaid, M. T., Kayali, O., Khennane, A., \& Black, J. (2015). A mix design procedure for low calcium alkali activated fly ash-based concretes. Construction and Building Materials, 79, 301310.

6. Bondar, D., Lynsdale, C. J., Milestone, N. B., Hassani, N., \&Ramezanianpour, A. A. (2011). Effect of adding mineral additives to alkaliactivated natural pozzolan paste. Construction and Building Materials, 25(6), 2906-2910.

7. Jindal, B. B. (2019). Investigations on the properties of geopolymer mortar and concrete with mineral admixtures: A review. Construction and Building Materials, 227, 116644.

8. Mallikarjuna Rao, G., \&Gunneswara Rao, T. D. (2018). A quantitative method of approach in designing the mix proportions of fly ash and GGBS-based geopolymer concrete. Australian Journal of Civil Engineering, 16(1), 53-63.

9. Siegel, J. A., Mirakovits, J. A., \& Hudson, B. (2013). Concrete mix design, quality control and specification. CRC Press.

10. Habert, G., De Lacaillerie, J. D. E., \&Roussel, N. (2011). An environmental evaluation of geopolymer based concrete production: reviewing current research trends. Journal of cleaner production, 19(11), 1229-1238.
11. Rangan, B. V., Hardjito, D., Wallah, S. E., \&Sumajouw, D. M. (2005, June). Studies on fly ash-based geopolymer concrete. In Proceedings of the World Congress Geopolymer, Saint Quentin, France (Vol. 28, pp. 133-137).

12. Hardjito, D., Wallah, S. E., Sumajouw, D. M., \&Rangan, B. V. (2004). On the development of fly ash-based geopolymer concrete. Materials Journal, 101(6), 467-472.

13. Huiskes, D. M. A., Keulen, A., Yu, Q. L., \&Brouwers, H. J. H. Design and performance evaluation of ultra-lightweight alkali activated concrete. PERFORMANCE OF ADMIXTURE AND SECONDARY MINERALS IN ALKALI ACTIVATED CONCRETE, 85.

14. Hadi, M. N., Zhang, H., \& Parkinson, S. (2019). Optimum mix design of geopolymer pastes and concretes cured in ambient condition based on compressive strength, setting time and workability. Journal of Building Engineering, 23, 301-313.

15. Ayub, T., Khan, S. U., \&Memon, F. A. (2014). Mechanical characteristics of hardened concrete with different mineral admixtures: a review. The Scientific World Journal, 2014.

16. BIS (Bureau of Indian Standards) 2019. IS 10262-2019: Indian standard concrete mix proportioning-guidelines (second revision). New Delhi: Bureau of Indian Standards.

17. Anchula Nagarjuna, T. Suresh Kumar, B.Yogeswara Reddy, M.Udaykiran, International Journal of Innovative Technology and Exploring Engineering, Vol. 8 no. 11, pp: 640-645, (2019)

18. Manjunatha, G. S., Radhakrishna, Venugopal, K., \&Maruthi, S. V. (2014). Strength characteristics of open air cured geopolymer concrete. Transactions of the indian ceramic society, 73(2), 149-156.

19. Ariffin, M., Azreen, M., Hussin, M. W., \&RafiqueBhutta, M. A. (2011). Mix design and compressive strength of geopolymer concrete containing blended ash from agro-industrial wastes. In Advanced Materials Research (Vol. 339, pp. 452-457). Trans Tech Publications Ltd.

20. Nath, S. K., Mukherjee, S., Maitra, S., \& Kumar, S. (2014). Ambient and elevated temperature geopolymerizationbehaviour of class f fly ash. Transactions of the Indian Ceramic Society, 73(2), 126-132.

21. Ng, T. S., \& Foster, S. J. (2013). Development of a mix design methodology for high-performance geopolymer mortars. Structural Concrete, 14(2), 148-156.

22. Ryu, G. S., Lee, Y. B., Koh, K. T., \& Chung, Y. S. (2013). The mechanical properties of fly ashbased geopolymer concrete with alkaline 
activators. Construction and Building Materials, 47, 409-418.

23. Singh, B., Ishwarya, G., Gupta, M., \& Bhattacharyya, S. K. (2015). Geopolymer concrete: A review of some recent developments. Construction and building materials, 85, 78-90.

24. Naspuri Arun Raju, T. Suresh Kumar, International Journal of Innovative Technology and Exploring Engineering, Vol. 8 no. 11, pp: 3860-3864, (2019).

25. Rao, G. M., \& Rao, T. G. (2015). Final setting time and compressive strength of fly ash and GGBS-based geopolymer paste and mortar. Arabian Journal for Science and Engineering, 40(11), 3067-3074.

26. Goriparthi, M. R., \& TD, G. R. (2017). Effect of fly ash and GGBS combination on mechanical and durability properties of GPC. Advances in concrete construction, 5(4), 313.

27. Al Bakria, A. M., Kamarudin, H., BinHussain, M., Nizar, I. K., Zarina, Y., \&Rafiza, A. R. (2011). The effect of curing temperature on physical and chemical properties of geopolymers. Physics Procedia, 22, 286-291.

28. Duxson, P., Provis, J. L., Lukey, G. C., \& Van Deventer, J. S. (2007). The role of inorganic polymer technology in the development of 'green concrete'. Cement and Concrete Research, 37(12), 1590-1597.

29. Patankar, S. V., Ghugal, Y. M., \&Jamkar, S. S. (2014). Effect of concentration of sodium hydroxide and degree of heat curing on fly ashbased geopolymer mortar. Indian Journal of Materials Science, 2014.

30. Tummala Suresh Kumar, Kosaraju Satyanarayana, Materials Today: Proceeding, 26 (2), 3228-3233, (2020).

31. Nath, P., \&Sarker, P. K. (2014). Effect of GGBFS on setting, workability and early strength properties of fly ash geopolymer concrete cured in ambient condition. Construction and Building Materials, 66, 163-171.

32. Saxena, S. K., Kumar, M., \& Singh, N. B. (2018). Effect of Alccofine powder on the properties of Pond fly ash based Geopolymermortar under different conditions. Environmental Technology \& Innovation, 9, 232-242.

33. Van Jaarsveld, J. G. S., Van Deventer, J. S. J., \&Lukey, G. C. (2003). The characterisation of source materials in fly ash-based geopolymers. Materials Letters, 57(7), 1272-1280.

34. A. Mehta, R. Siddique, Properties of low-calcium fly ash based geopolymer concrete incorporating OPC as partial replacement of fly ash, Constr. Build. Mater. 150, 792-807 (2017).
35. Deb, P. S., Nath, P., \&Sarker, P. K. (2014). The effects of ground granulated blast-furnace slag blending with fly ash and activator content on the workability and strength properties of geopolymer concrete cured at ambient temperature. Materials \& Design (1980-2015), 62, 32-39. 